\begin{tabular}{|c|c|c|c|}
\hline$\Omega$ & D & $\equiv$ & (2) \\
\hline $\begin{array}{l}\text { Sharon Mitchell1 } \\
\text { Fabio Pitta } 2 \\
\text { Thierry Troosters } 3 \\
\text { On behalf of } \\
\text { the respiratory } \\
\text { physiotherapy } \\
\text { HERMES task force }\end{array}$ & $\begin{array}{l}1 \text { European Respiratory } \\
\text { Society, Lausanne, } \\
\text { Switzerland. } 2 \text { Dept of } \\
\text { Physiotherapy-CCS, State } \\
\text { University of Londrina, } \\
\text { Londrina, Brazil. } 3 \text { Dept of } \\
\text { Rehabilitation Sciences, } \\
\text { Katholieke Universiteit } \\
\text { Leuven, Leuven, Belgium. }\end{array}$ & $\begin{array}{l}\text { S. Mitchell: } \\
\text { European Respiratory } \\
\text { Society, 4, Avenue } \\
\text { Ste-Luce, CH } 1003 \\
\text { Lausanne, Switzerland }\end{array}$ & sharon.mitchell@ersnet.org \\
\hline
\end{tabular}

\title{
Standardised education and training for respiratory physiotherapists
}

The mission of ERS is to alleviate suffering from respiratory disease and to promote lung health through research, sharing of knowledge and through medical and public education. Within this context, respiratory physiotherapy plays a fundamental role in improving ventilation, and enhancing quality of life [1] for patients with respiratory disease. Physiotherapists work with patients in a variety of settings including patients' homes, pulmonary rehabilitation programmes, wards and intensive care units. Although physiotherapy is globally recognised within the healthcare profession, some respiratory physiotherapy techniques have been clouded by a lack of scientific evidence [2] and insufficient clinical data [3] on the benefits of specific techniques in the treatment of patients suffering from respiratory disease. In recent decades, evidence (or absence thereof) has been emerging for many techniques related to exercise training, mucus transport and breathing retraining strategies. The field is rapidly evolving. In 1995 a specific group involving respiratory physiotherapists was established. This active group exists under the European Respiratory Society assembly for allied health professionals (ERS group 9.02), and gathers annually during the ERS Annual Congress, keeping an open channel of communication with physiotherapists throughout the year.

STILLER [3] reported that while "some physiotherapists routinely treat most if not all ICU patients with a combination of techniques, [...] other physiotherapists use such techniques selectively when they believe they are specifically indicated", thereby highlighting the differences in treatment of patients by respiratory physiotherapists just over a decade ago. In 2009, ВотT et al. [2] published guidelines with the distinct purpose of producing evidence-based recommendations for practice. In recent years, great strides have been taken in research of respiratory physiotherapy to accumulate and report on the supporting rationale and effectiveness of respiratory physiotherapy techniques and combinations of techniques used in treatment [2-6]. Considering a surge in reported research, the production of guidelines and the growth in the number of centres of excellence [2], the discipline of respiratory physiotherapy has set foundations for standardisation of practice and consequently improved care for patients. Leaders within the field now plan to pursue harmonisation of the training and certification of this expert group, address "the need to standardise pathways for clinical decision making and education" and "define the professional profile of physiotherapists" [4].

\section{Europe's call for harmonisation of third-level education and training}

In 1999, European ministers of education issued the Bologna declaration to establish
Statement of Interest

S. Mitchell is an employee of ERS. 
the European area of higher education and to promote the European system of higher education worldwide. This declaration sought curriculum improvement, quality assurance, qualifications frameworks, recognition, mobility and social equity [7]. Following this call for educational reform, the EU Parliament and Council Directive 2005/36/EC, 2005 focused more specifically on medical education within Europe outlining the overarching goal of formal recognition of European primary medical degrees as well as postgraduate specialist qualifications anywhere within Europe [8]. While projects including the Tuning project and MEdInE (medical education in Europe) have looked towards improving training and qualifications of undergraduate medical education with support from the European Commission, HERMES (Harmonised Education in Respiratory Medicine for European Specialists) was launched in 2005 with the sole purpose of providing a framework to produce standardised criteria for training and certification within the field of respiratory medicine.

\section{Harmonised Education in Respiratory Medicine for European Specialists}

The ERS has led this effort to standardise postgraduate medical education within the field of

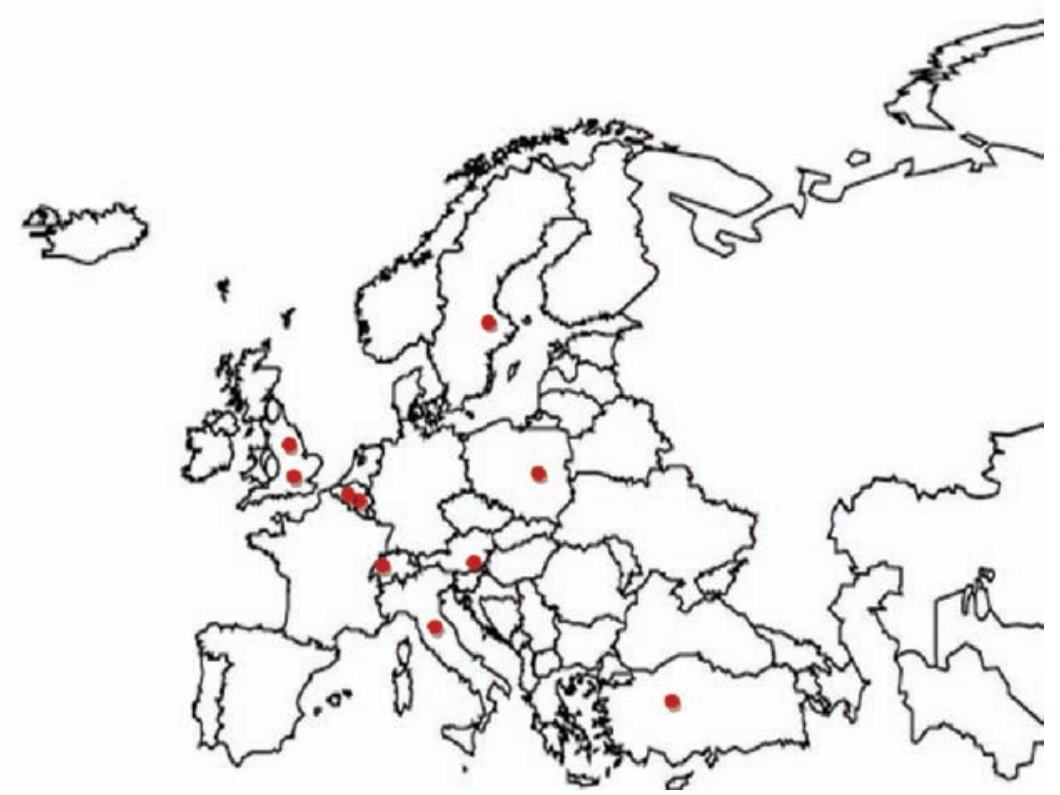

Figure 1. Countries represented by the Respiratory Physiotherapy HERMES Task Force; one task force member is based in Brazil. respiratory medicine and has established a methodological structure to develop consensus criteria and activities to support development of syllabi, curricula and assessments. This structure seeks to address a disconnect in the knowledge and skills of those who qualify and practice within the specialties of respiratory medicine. This initiative has been expanded to a number of specialties within respiratory medicine, and project task forces have produced activities in support of the documented syllabi and curricula, such as educational courses, online learning modules, textbooks, websites, examinations and an accreditation process for training centres. HERMES documents and activities are recognised as a mark of excellence across European national societies. The HERMES examination in adult respiratory medicine for example was afforded legal recognition as an official part of their exit examination for Swiss trainees. Austria too recognises the HERMES examination as equivalent to its written knowledge examination and the Netherlands have adopted the HERMES examination as a formative assessment for all Dutch trainees. Collaborative contracts with other European societies and national societies afford the HERMES project value, esteem and respect within Europe.

\section{Respiratory Physiotherapy HERMES Task Force}

The primary justification of the application of the HERMES methodology to respiratory medicine specialites is grounded in the results of a needs analysis survey undertaken by the HERMES task forces. In September 2012, the respiratory physiotherapy HERMES task force (fig. 1) representing nine countries assembled for its first meeting to discuss the application of the HERMES methodology to this specialist area. The aim of this HERMES task force is to develop a postgraduate training programme in respiratory physiotherapy prescribing core modules. The syllabus of this postgraduate training programme will include those knowledge items and skills required to practice as a specialist in respiratory physiotherapy. The curriculum will translate how those items listed within the syllabus should be taught.

Before the HERMES methodology can be fully applied to develop a respiratory physiotherapy postgraduate training programme, it is important to first realise the disparities of training and 
certification of respiratory physiotherapy within and beyond European boundaries. The training level may vary from a professional bachelor degree in some countries to MSc or PhD level in other countries. As a consequence, the legal role of a physiotherapist differs greatly between countries. A survey was designed not only to assess current training practices but also to investigate who within the multidisciplinary team is responsible for diagnosis and implementation of respiratory physiotherapy techniques. The results of this preliminary survey are key to the planning and intended outputs of the respiratory physiotherapy task force. For the purpose of this editorial, only the main findings have been included and a full report on the survey may be found on the HERMES website (hermes.ersnet.org).

\section{Needs analysis: survey results}

A total of 105 participants completed the needs analysis online survey representing 36 countries worldwide (fig. 2). All were members of ERS, which admittedly may have lead to a bias towards professionals with a higher education level.

The first survey questions investigated general physiotherapy as a graduate training programme. General physiotherapy training may be organised either as a professional training programme including a period of work integrated into academic training or alternatively as an academic training programme at a University. $64.1 \%$ of respondents reported that physiotherapy training is organised as an academic training programme with $44.6 \%$ of those respondents reporting that undergraduate training takes 3 years to complete and $32.3 \%$ reporting that training modules are dispersed over 4 years. In line with the Bologna agreement, from the survey results, it appears that although some variations exist, undergraduate training and certification for physiotherapy follows specific training modules at third-level education.

The following survey questions addressed training practices in respiratory physiotherapy and asked participants to provide information on how this training is organised in their country.

\section{Do you have a specific syllabus or training programme for respiratory physiotherapy in your country?}

Of the 98 respondents who completed this survey question, 61 participants reported that there was no syllabus dedicated to training in respiratory physiotherapy.

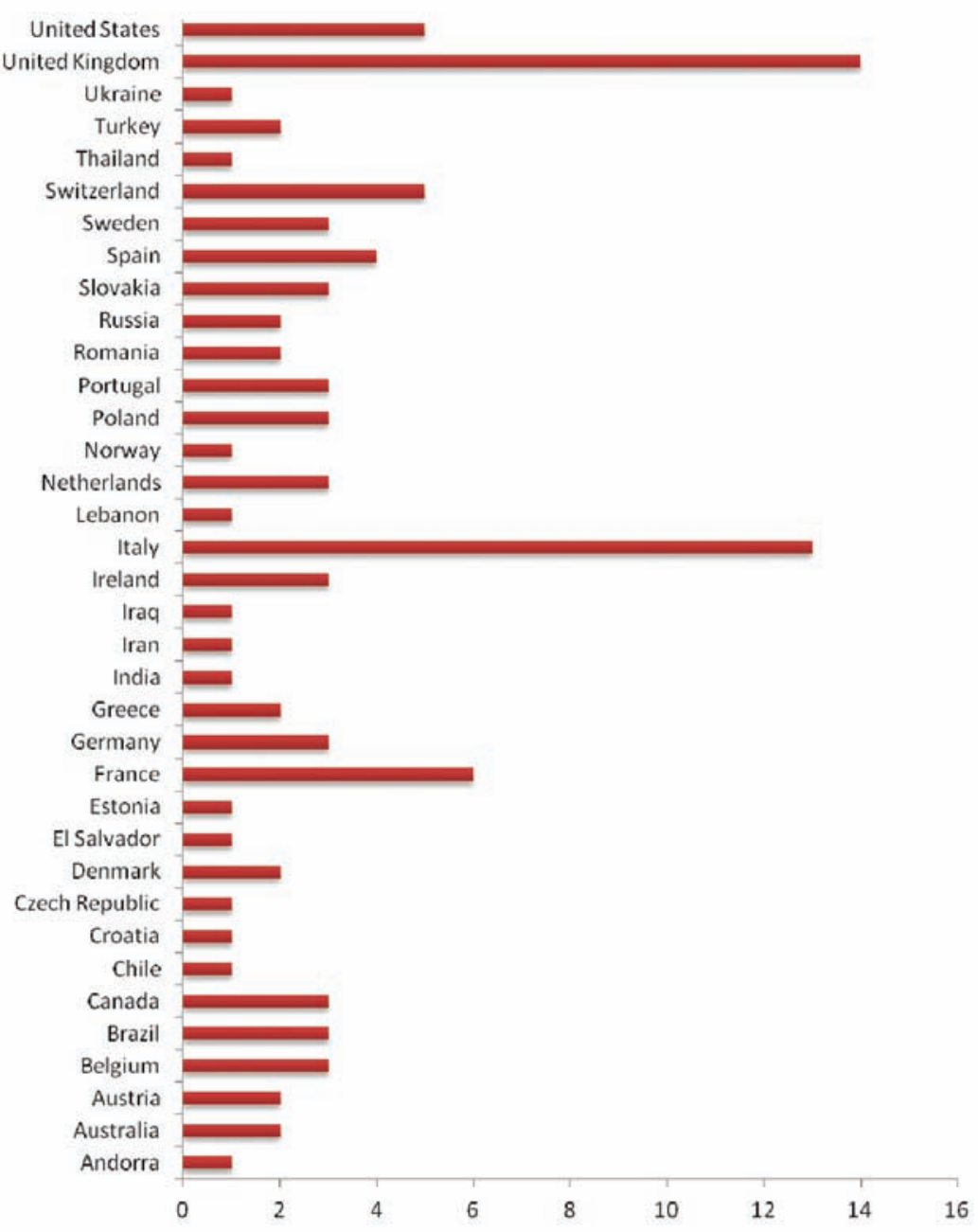

Figure 2. Number of respondents from each country in the study.

Is respiratory physiotherapy training organised as a postgraduate training programme following general physiotherapy training?

If we delve a little further into the responses there are a number of countries that do not have a postgraduate training programme dedicated to respiratory physiotherapy which is formally organised and evaluated. A lack of uniformity within national training systems is also evident with conflicting reports received from Belgian and Danish respondents, for example. Respondents' comments further highlight disparities in training within national borders. One respondent stated "It is difficult to answer many questions, because practice varies from area to area."

Extreme variations in assessment of training in respiratory physiotherapy also exist across countries with $67 \%$ of country representatives reporting that no specialty examination exists within respiratory physiotherapy.

The results of this survey support the 
justification and rationale to develop a standardised framework for the education and certification of postgraduate respiratory physiotherapy. In line with the European Commission's plans to recognise undergraduate and postgraduate qualifications across European boundaries, and through the application of the HERMES methodology, it is the intention of the respiratory physiotherapy HERMES task force to standardise the training and practice of respiratory physiotherapy which can be applied not only within Europe but also beyond European boundaries.

\section{Conclusion}

If we reconsider the ERS mission to alleviate suffering from respiratory disease, then there is little doubt that education is one of the primary factors to be addressed in order to improve the practice of respiratory medicine specialties and thus the quality of care to patients. Respiratory physiotherapy also falls within this domain. From results of the preliminary survey assessing training practices across countries, there is a clear disconnect not only across international boundaries but also across national borders. It is intended that the production of standardised documentation will harmonise training and certification of the respiratory physiotherapist. Building on the achievements of researchers in the field, the respiratory physiotherapy HERMES task force will take a step towards the overarching goal of improving the quality of care for patients with respiratory diseases.
References

1. Gerrod R, Lasserson T. Role of physiotherapy in the management of chronic lung diseases. Respir Med 2007; 101: 2429-2436.

2. Bott J, Blumenthal S, Buxton M, et al. Guidelines for the physiotherapy management of the adult, medical, spontaneously breathing patient. Thorax 2009; 64: i1-i51.

3. Stiller K. Physiotherapy in Intensive Care: Towards an evidence-based practice. Chest 2000; 118: 1801-1813.

4. Gosselink R, Bott J, Johnson M, et al. Physiotherapy for adult patients with critical illness: recommendations of the European Respiratory Society of Intensive Care Medicine Task Force on Physiotherapy for Critically III Patients. Intensive Care Med 2008; 34: 1188-1199.

5. Clini E, Ambrosino N. Early physiotherapy in the respiratory intensive care unit. Respir Med 2005; 99: 1096-1104.
6. Langer D, Hendriks E, Burtin C, et al. A clinical practice guideline for physiotherapists treating patients with chronic obstructive pulmonary disease based on a systematic review of available evidence. Clin Rehabil 2009; 23: 445-462.

7. European Commission. The EU and the Bologna Process: shared goals, shared commitments supporting growth and jobs. An agenda for the modernisation of Europe's higher education systems 20.09.2011. Online: http://ec.europa.eu/education/higher-education/bologna_en.htm Date last accessed: 15 January 2013.

8. European Commission. Directive 2005/36/EC of the European Parliament and of the council 24.03.2011.Online:http://ec.europa.eu/ internal_market/qualifications/policy_developments/legislation/index_ en.htm\#directive Date last accessed: 15 January 2013. 